\title{
THEORETICAL STUDIES ON THE NEW HIGH-NITROGEN EXPLOSIVES N14 AND N18
}

\author{
Jifeng Chen ${ }^{\mathrm{a}}$, Yi Yu ${ }^{\mathrm{b}}$, Yuchuan $\mathrm{Li}^{\mathrm{a}, *,(1)}$ and Siping Pang, \\ ${ }^{a}$ School of Materials Science \& Engineering, Beijing Institute of Technology, 100081 Beijing - PR, China \\ ${ }^{b}$ Research Institute of Aerospace Special Materials and Processing Technology, 100074 Beijing - PR, China
}

Recebido em 10/02/2019; aceito em 18/07/2019; publicado na web em 30/08/2019

\begin{abstract}
The power of a compound is enhanced by the direct connection of nitrogen atoms, and its stability can be improved through conjugated structure. So novel high energy density materials N14 (1,6-dihydro-1,2,3,3a,4,5,5a,6,7,8,8a,9,10,10a-tetradecazapyrene) and N18 (1,2,2a,3,4,4a,5,6,6a,7,8,8a,9,10,10a,11,12a-octadecazacoronene) were designed, and their structures, detonation performance, and stabilities were calculated employing density functional theory (DFT). The detonation performance includes detonation pressure (P), detonation velocity (D), and heat of detonation (Q). Furthermore, the stability involves frontier molecular orbitals and impact sensitivity. Calculations reveal that they have an excellent power, detonation performance of N14 ( $\mathrm{P}=43.6 \mathrm{GPa}$, $\left.\mathrm{D}=10040 \mathrm{~m} \mathrm{~s}^{-1}, \mathrm{Q}=2214 \mathrm{cal} \mathrm{g}^{-1}\right)$ and $\mathrm{N} 18\left(\mathrm{P}=37.4 \mathrm{GPa}, \mathrm{D}=9400 \mathrm{~m} \mathrm{~s}^{-1}, \mathrm{Q}=2114 \mathrm{cal} \mathrm{g}^{-1}\right)$ are comparable to CL-20. Besides, their impact sensitivities are slightly better than CL-20, therefore they are promising candidates in energetic materials.
\end{abstract}

Keywords: N14; N18; density functional theory (DFT); high energy; high-nitrogen.

\section{INTRODUCTION}

High energy density materials (HEDMs), which possess not only perfect detonation performance, but also good thermal stability and low sensitivity, have attracted considerable interest for some potential applications in propellants, explosives, and pyrotechnic agents in recent years. ${ }^{1-3}$ In order to meet the main requirements in safety and power, much effort has been made by a large number of research groups ${ }^{4-7}$ However, in most cases, it is very difficult to concentrate both desired properties into one substance. Traditional energetic materials (HMX, RDX, CL20, etc.) are developing toward a bottleneck stage.

Polynitrogen materials have received much more attention on their high energy content due to the deviation of bond energy of the $\mathrm{N}_{2}$ triple bond and N-N single bonds or double bonds. ${ }^{8}$ However, most of them are unstable. Since 1999, a series of $\mathrm{N}_{5}{ }^{+}$-containing salts have been investigated and the most stable $\mathrm{N}_{5}{ }^{+}$-containing salt $\mathrm{N}_{5}{ }^{+} \mathrm{SbF}_{6}{ }^{-}$is only stable at about $60{ }^{\circ} \mathrm{C} .{ }^{7}$ In 2004 , polymeric nitrogen with a cubic gauche structure was produced by Eremets. ${ }^{9}$ Its power is five times greater than that of the most powerfully energetic materials, whereas it disappears at ambient pressure. In 2017, two significant breakthroughs in the bulk synthesis and characterization of the pentazolate anion cyclo- $\mathrm{N}_{5}{ }^{-}$salts were achieved by $\mathrm{Lu}$ and $\mathrm{Hu}$, respectively. ${ }^{5,10}$ Recently, the most stable cyclo- $\mathrm{N}_{5}^{-}$salts, $\mathrm{Na}_{24} \mathrm{~N}_{60}$ and $\mathrm{Na}_{20} \mathrm{~N}_{60}$, occur only below $148^{\circ} \mathrm{C} .{ }^{11}$ Additionally, some other all-nitrogen materials cannot exist under room temperature for a long period. ${ }^{8,12}$

New high energy density materials are considered under the circumstances. Two novel covalent compounds, N14 and N18, are designed in this paper with the characteristics of great power and high safety, whose chemical structures are shown in Figure 1. There are 14 nitrogen atoms closely linked in N14, and 18 nitrogen atoms in N18. In these structures, several nitrogen atoms connected directly can enhance energy. However, in most cases, high nitrogen content and stability tend to be mutually exclusive. ${ }^{4}$ Thereby olefin and benzene ring are expected to form a large $\pi$ bond with nitrogen atoms to improve its stability, though the large conjugated bonds do not

*e-mail: liyuchuan@bit.edu.cn

\#alternative e-mail: pangsp@bit.edu.cn appear. The $\mathrm{C}_{12} \mathrm{~N}_{12}$ structure, being similar to N18, was reported, and Monda ${ }^{13}$ indicates that is slightly aromatic in nature, but Tursungul ${ }^{14}$ does not agree with him.<smiles>c1c2n3nnnnn-2nnn1[nH]nn3</smiles>

N14<smiles></smiles>

N18
Figure 1. Chemical structure of the title compounds

Theoretical studies of N14 and N18 make it not only possible to provide a forecast of the properties of candidate compounds, but it is also possible to compare them. The theoretical density $(\rho)$, the heat of formation (HOF), and the detonation performance is emphasized to explain their high energy. At the same time, the molecular geometries' structures, impact sensitivity $\mathrm{h}_{50 \%}$ and electrostatic potential (ESP) is present to illustrate their relatively stable. Besides, the frontier molecular orbitals and possible synthetic routes are also expounded. These results can be used for comparison with the properties of some familiar explosives and polynitrogen materials, providing theoretical support for the molecular design of novel high energy density compounds.

\section{COMPUTATIONAL DETAILS}

Computations were performed with the Gaussian 09 package at the B3LYP level ${ }^{15}$ method with the $6-311++\mathrm{G}(\mathrm{d}, \mathrm{p})$ basis set. The B3LYP method is a common and effective way to evaluate energetic compounds, which was mentioned in previous papers. ${ }^{16-19}$ The molecular geometries and electronic structures were obtained with the density functional theory (DFT) method. The geometric parameters of these two structures were allowed to be optimized, and no constraints were imposed on the molecular structures during the 
optimization process. Structures were identified to be local minima without imaginary frequencies.

The geometric structure refers to the bond length and bond angle in this paper. Bond length is one important parameter for a molecule. Commonly, the bond length is closely related with the bond stability: the longer the bond length is, the less stable the bond is ${ }^{20}$ Bond angle is another important parameter for a molecule and $108^{\circ}$ is an excellent value. ${ }^{17}$

Molecular electrostatic potentials (ESP) are used to describe the interaction of static electricity in molecules, and to predict chemical reactivity sites. The results of ESP can be viewed and analyzed by the visual molecular dynamics (VMD), which is a molecular modelling and visualization computer program. ${ }^{21}$ With the help of the VMD program, the very nice color-filled molecular surface maps with surface extrema can be plotted based on the output of the Multiwfn program. ${ }^{22}$ In the maps, Figures 7 and 8, the green and orange spheres correspond to significant minima and maxima ESP surfaces, respectively. These spheres are labeled by dark blue and brown-red texts with the unit $\mathrm{kcal} \mathrm{mol}^{-1}$. At the same time, the global minima and maxima on the surface are labeled by larger and italic font.

The isodesmic reactions were used to predict the heat of formation (HOF) of compounds, and isodesmic reactions of N14 and N18 are shown in Figures 2 and 3. The enthalpy of reaction $\left(\Delta_{\mathrm{r}} \mathrm{H}_{298}\right)$ at $298 \mathrm{~K}$ can be calculated according to Equation (1) in the isodesmic reaction. The $\Delta_{\mathrm{f}} \mathrm{H}_{\mathrm{P}}$ and $\Delta_{\mathrm{f}} \mathrm{H}_{\mathrm{R}}$ of the following equation are the HOFs of products and the reactants, respectively. Similarly, $\Delta \mathrm{E}_{0}, \Delta \mathrm{E}_{\mathrm{ZPE}}$, and $\Delta \mathrm{H}_{\mathrm{T}}$ are the differences between products and reactants. Furthermore, the $\mathrm{E}_{0}$ is the total energy at $0 \mathrm{~K}$ and the $\Delta \mathrm{H}_{\mathrm{T}}$ is the thermal correction from $0 \mathrm{~K}$ to $298 \mathrm{~K}$. The $\mathrm{E}_{\mathrm{ZPE}}$ is zero-point energy, which means the difference between the lowest possible energy that a quantum mechanical system may have, and the classical minimum energy of the system.

According to Equation (1), the heat of formation of the gaseous $\mathrm{N} 14$ and $\mathrm{N} 18 \Delta_{\mathrm{f}} \mathrm{H}(\mathrm{g})$ can be calculated, while the heat of formation in the condensed phase $\Delta_{\mathrm{f}} \mathrm{H}(\mathrm{c})$ is determined by Equation (2). In order to estimate $\Delta \mathrm{H}_{\text {sub }}$, the electrostatic potential method ${ }^{23}$ can be used, as shown in Equation (3). In the equation (3) and (4), $A_{s}$ is molecular surface area. And $\sigma_{\text {tot }}^{2}$ is total variance on the molecular surface, which is the sum of positive and negative parts and reflects the variability of molecular electrostatic potentials. The $v$ is electrostatic balance parameter, and the value of $v \sigma_{\text {tot }}^{2}$ indicates that a molecule has relatively strong tendencies to interact with others of its own kind electrostatically. Finally, these parameters can be calculated by Multiwfn software. ${ }^{22}$

$$
\begin{aligned}
\Delta_{\mathrm{r}} H_{298} & =\sum \Delta_{f} H_{P}-\sum \Delta_{f} H_{R} \\
& =\Delta E_{0}+\Delta E_{Z P E}+\Delta H_{T}+\Delta n R T
\end{aligned}
$$

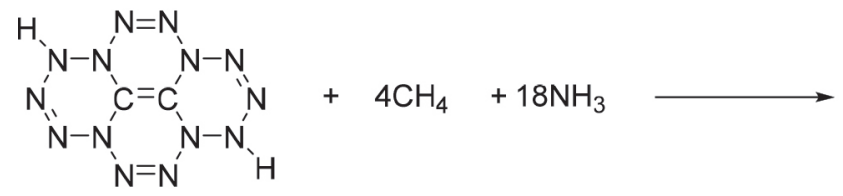

Figure 2. The isodesmic reaction of $\mathrm{N} 14$

$$
\begin{gathered}
\Delta_{f} H(c)=\Delta_{f} H(g)-\Delta H_{\text {sub }} \\
\Delta H_{\text {sub }}=0.000267\left(A_{s}\right)^{2}+1.650087\left(v \mathrm{~s}_{\text {tot }}^{2}\right)^{0.5}+2.966078
\end{gathered}
$$

In the high energy density material, the crystal density $(\rho)$ is an important parameter for predicting performance. Equation (4) proposed by Politzer et al. ${ }^{24}$ was used to calculate the crystal density of compounds where $\mathrm{M}$ is the molecular weight and $\mathrm{Vm}$ is the molecular volume defined as the inside of a contour of 0.001 au density that was evaluated using Monte Carlo integration. Finally, $\alpha, \beta$, and $\gamma$ here are $0.9183,0.0028$, and 0.0443 , respectively.

$$
\rho=\alpha\left(\frac{M}{V_{m}}\right)+\beta\left(v \sigma_{t o t}^{2}\right)+\gamma
$$

Detonation pressure $(\mathrm{P}, \mathrm{GPa})$, detonation velocity $\left(\mathrm{D}, \mathrm{km} \mathrm{s}^{-1}\right)$, and heat of detonation $\left(\mathrm{Q}, \mathrm{cal} \mathrm{g}^{-1}\right)$ reflecting the explosive performance of energetic materials, were estimated using EXPLO 5 (v6.01).

The frontier molecular orbitals include the lowest unoccupied molecular orbital (LUMO) and the highest occupied molecular orbital (HOMO). Long-range corrected hybrid functionals ( $\omega$ B97X-D) are considered to be more accurate than global hybrid functionals (B3LYP) when predicting the energy gap, ${ }^{25}$ while the two methods were used in the paper to illustrate the fact well.

Impact sensitivity is an important index to evaluate explosives, and $\mathrm{h}_{50 \%}$ is a common value to assess the index. The $\mathrm{h}_{50 \%}$ is the height where $50 \%$ probability of the "drop" results in a reaction of the sample. The shorter the drop height is, the greater the impact sensitivity is. The value is difficult to measure experimentally and strongly depend on morphology, crystal shape and size and impurities. Predicting it with any reliability is even more difficult, but Equation (5) can estimate it approximately. In the equation, $\alpha_{2}, \beta_{2}$, and $\gamma_{2}$ are $-0.0064,241.42$, and -3.43 , respectively. ${ }^{26}$

$$
h_{50 \%}=\alpha_{2} \sigma_{+}^{2}+\beta_{2} v+\gamma_{2}
$$

\section{RESULTS AND DISCUSSION}

\section{Geometrical structures}

The structure of N18 is similar to that of coronene, with periphery nitrogen atoms replacing carbon atoms. Some of periphery nitrogen atoms form double bonds while some form single bonds, and the middle carbon forms the benzene ring. We hope that the nitrogen atoms with single bonds, which carry lone-pair electrons, form larger conjugated systems with the benzene ring and a large number of azo
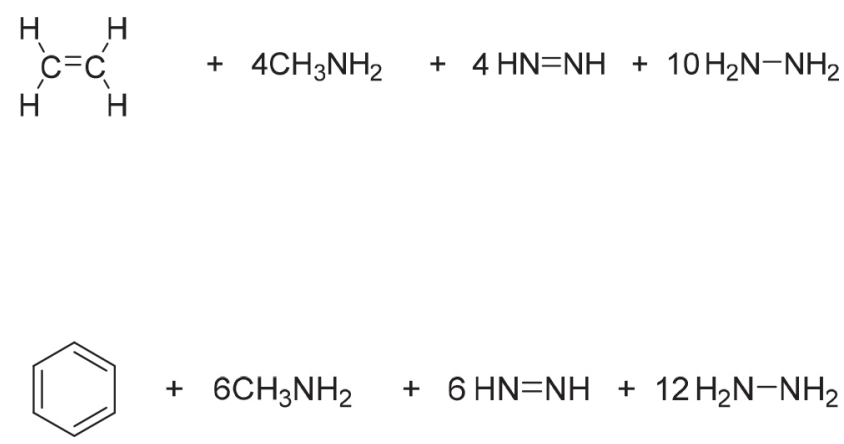

Figure 3. The isodesmic reaction of $N 18$ 
bonds. However, the output result of the B3LYP method shows that all atoms are not coplanar, so N18 may be not an aromatic compound. The structure output of N18 is shown in Figure 4. Six carbon atoms of the benzene ring form large $\pi$ bonds in the input structure, but they are linked together with double bonds in the output structure. This is not corrected for the sake of keeping the raw data. More information on standard orientation of every atom was presented in Supporting Information in detail.

In this structure, all carbon atoms are in the same plane and each C-C bond length is $1.3707 \AA$, which is shorter than that of benzene (1.3945 $\AA$ ). All of the double-bond nitrogen atoms are also in the same plane and the distance of the N-N double bond (each one is $1.2389 \AA$ ) is shorter than that of azobenzene (1.2522 ̊). Similarly, six single-bond nitrogen atoms are placed on the same plane while the N-N single bond of the compound (1.4398 $\AA$ ) is close to that of hydrazine (1.4310 $\AA$ ) and $\mathrm{C}-\mathrm{N}$ single bonds of the compound $(1.3921 \AA)$ are shorter than $\mathrm{C}-\mathrm{NO}_{2}$ of TATB $(1.4366 \AA)$. The bond lengths of the mentioned benzene, azobenzene, hydrazine, and TATB are calculated using the same method with N18. In this structure, $\mathrm{C} 2-\mathrm{C} 1-\mathrm{C} 3=120.0^{\circ}, \mathrm{N} 8-\mathrm{C} 4-\mathrm{C} 2=119.8^{\circ}, \mathrm{N} 7-\mathrm{N} 8-\mathrm{C} 4=114.2^{\circ}$, N7-N8-N9 $=109.1^{\circ}$, and N8-N9-N10 $=121.7^{\circ}$. Since N18 has a symmetrical structure, other bond angles have the same value and all bond angles are approximately $108^{\circ}$. Therefore, single-bond nitrogen atoms, double-bond nitrogen atoms, and carbon atoms are not on the same plane and form a large conjugated system, but they have special interactions to become a stable structure. Some bond lengths and bond angles of N18 are listed in Table 1.

The structure of N14 is similar to that of pyrene, with periphery nitrogen atoms replacing carbons atoms. Moreover, it possesses two additional hydrogen atoms because nitrogen has three valence bonds. We hope that the nitrogen atoms with single bonds, which carry lone-pair electrons, form a larger conjugated system with the C-C double bond and many azo bonds. Just like N18, the output result with the B3LYP method shows that all atoms are not coplanar, so N14 may not be an aromatic compound. The structure output of N14 is shown in Figure 5.

In the structure of $\mathrm{N} 14$, the $\mathrm{C}-\mathrm{C}$ double bond has a bond length of $1.3122 \AA$, which is shorter than that of ethylene (1.3288 $⿱$ ). The distance between N3-N4 and N9-N10 is $1.2523 \AA$, while that of N6-N7 and N12-N13 is $1.2324 \AA$, and they are close to their counterpart of azobenzene. Two C-N bond lengths are 1.3922 and $1.3921 \AA$, respectively, which are shorter than $\mathrm{C}-\mathrm{NO}_{2}$ of TATB. The N-H bond length is $1.0151 \AA$, which is close to that of $\mathrm{NH}_{3}$ (1.0147 $\AA$ ), calculated with same method and basis set. All N-N single bond lengths of N14 are listed in Table 2. Some of them are shorter than that of hydrazine, and some of them are slightly longer, but close to it. In the structure of N14, some bond angles are also listed in Table 2 and other bond angles have the same value for the symmetrical structure. From the table, it can be seen that all bond angles are close to $108^{\circ}$. As in the situation with N18, not all atoms in N14 are on the same plane and form a large conjugated system, but they have special interactions to become a stable structure. More information on output result of N14 was presented in Supporting Information in detail.

\section{Frontier molecular orbitals}

The LUMO (a) and HOMO (b) orbits of N14 and N18 are show in Figure 6. The positive phase is red and the negative one is green. Either LUMO or HOMO doesn't locate on H atom of N14, and the two orbits locate approximately on all the atoms of N18. Energy gaps of two compounds were calculated with B3LYP and $\omega$ B97X-D listed in Table 3. The values of $\Delta \mathrm{E}_{\mathrm{LUMO} \text {-номо }}$ are small, but it only reflects photochemistry stability. Natural bond orbital (NBO) analysis is an essential tool for studying interactions among bonds, and the orbital charges are summarized in the Supporting Information.
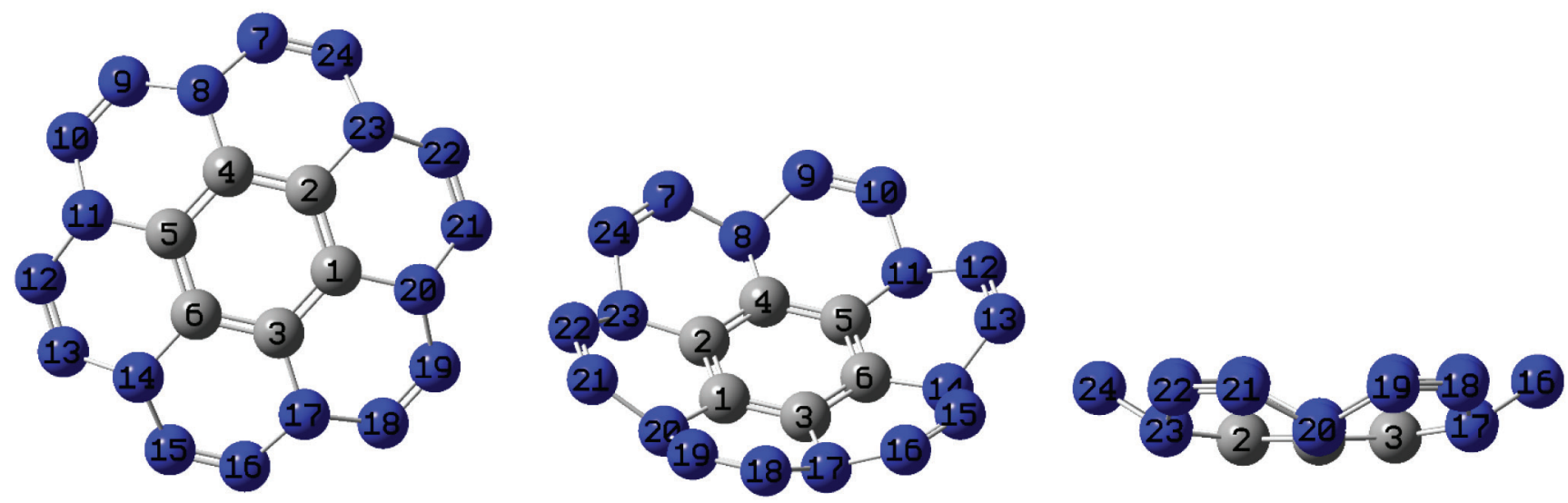

Figure 4. Structure of N18
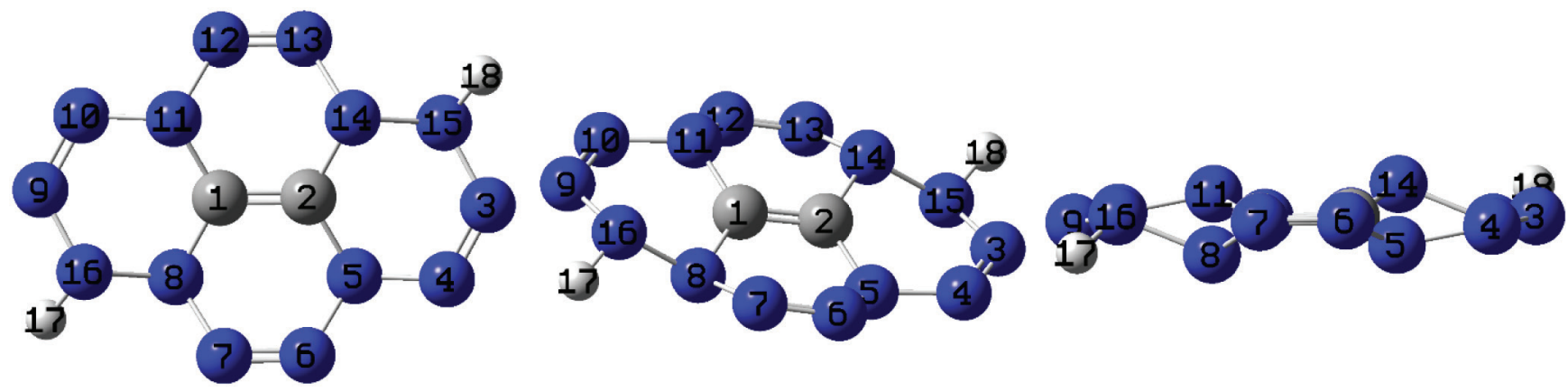

Figure 5. Structure of N14 
Table 1. Some bond lengths and bond angles of N18

\begin{tabular}{cccc}
\hline Bond & Bond length $(\AA)$ & Bond & Bond angles $\left(^{\circ}\right)$ \\
\hline C1-C2 & 1.3707 & C2-C1-C3 & 120.0 \\
C1-N20 & 1.3921 & N8-C4-C2 & 119.8 \\
N7-N8 & 1.4398 & N7-N8-C4 & 114.2 \\
N9-N10 & 1.2389 & N7-N8-N9 & 109.1 \\
& & N8-N9-N10 & 121.7 \\
\hline
\end{tabular}

Table 2. Some bond lengths and bond angles of N14

\begin{tabular}{cccc}
\hline Bond & Bond length $(\AA)$ & Bond & Bond angles $\left(^{\circ}\right)$ \\
\hline N4-N5 & 1.3950 & N9-N16-N8 & 115.3 \\
N9-N16 & 1.3874 & N16-N8-N7 & 110.4 \\
N5-N6 & 1.4323 & N8-N7-N6 & 119.0 \\
N8-N16 & 1.4634 & N7-N6-N5 & 119.4 \\
N7-N8 & 1.4757 & N6-N5-N4 & 113.0 \\
N10-N11 & 1.3949 & N5-N4-N3 & 117.8 \\
N3-N15 & 1.3873 & N4-N3-N15 & 122.2 \\
N11-N12 & 1.4319 & N3-N15-H18 & 106.4 \\
N14-N15 & 1.4634 & & \\
N13-N14 & 1.4756 & & \\
\hline
\end{tabular}

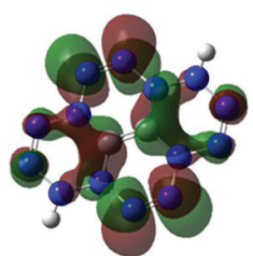

a

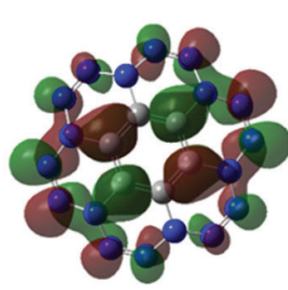

c

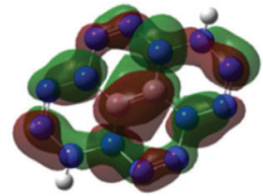

$\mathrm{b}$

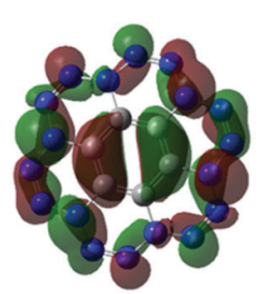

d
Figure 6. LUMO (a) and HOMO (b) orbitals of N14; and LUMO (c) and HOMO $(d)$ orbitals of $N 18$

\section{Electrostatic potentials}

The electrostatic potential map of the molecular surface (a) and the surface areas in each ESP range (b) of N14 are plotted and shown in Figure 7. The surface minima of ESP is distributed near some $\mathrm{N}$ atoms due to these atoms with double bonds or lone-pair electron, which are the primary electrophilic sites. The global minima site of
ESP is present near the N3 atom, with the value $-24.03 \mathrm{kcal} \mathrm{mol}^{-1}$. The global maxima site of ESP is $+52.67 \mathrm{kcal} \mathrm{mol}^{-1}$, which is close to that of the $\mathrm{H} 18$ atom since nitrogen atoms attract a lot of electrons. However, it may not be easily attacked by the nucleophile since $\mathrm{H} 18$, with the maxima in a monomer, and $\mathrm{N}$, with surface minima in neighboring monomer product hydrogen bond, will result in the electrostatic potentials cancelling each other out. The same applies to $\mathrm{H} 17$, with the other global maxima site at $+52.62 \mathrm{kcal} \mathrm{mol}^{-1}$. From Figure 7(b), it can be seen that a large portion has a small ESP value from -25 to $+25 \mathrm{kcal} \mathrm{mol}^{-1}$. The negative part mainly corresponds to the surface above and below the several $\mathrm{N}$ atoms with the effect of the abundant lone-pair electron or $\pi$-electron cloud. The largest positive area mainly arises from the $\mathrm{C}-\mathrm{C}$ double bond, and the smaller ones with remarkable positive ESP values correspond to the $\mathrm{C}-\mathrm{H}$ bond, though these are not nucleophilic sites.

The electrostatic potential map of the molecular surface (a) and the surface areas in each ESP range (b) of N18 is plotted and shown in Figure 8. The surface minima of ESP are distributed in the peripheral of the $\mathrm{N}$-atom ring and their values range from -17.15 to $-17.16 \mathrm{kcal} \mathrm{mol}^{-1}$, which is close to global minima. The N25 is near the global minima site, with the value $-17.16 \mathrm{kcal} \mathrm{mol}^{-1}$. Just like the minima, the surface maxima ranges from +42.00 to $+42.14 \mathrm{kcal} \mathrm{mol}^{-1}$, which is close to the global maxima $+42.17 \mathrm{kcal} \mathrm{mol}^{-1}$. They are located on the periphery of the benzene ring and on the same side as the global minima site. It can be seen that positive and negative potentials are distributed more evenly over the surface. There is a large portion ESP distributing from -20 to $+30 \mathrm{kcal} \mathrm{mol}^{-1}$, as shown in Figure 8(b). Obviously, the positive part arises from the $\mathrm{N}$ atom and the negative one comes from the $\mathrm{C}$ atom.

\section{Heats of formation}

The gas phase heat of formation of N14 and N18 can be calculated according to Figure 2, 3 and Equation (1). The experimental gas phase heat of formation of $\mathrm{NH}_{3}, \mathrm{CH}_{4}, \mathrm{C}_{6} \mathrm{H}_{6}, \mathrm{CH}_{3} \mathrm{NH}_{2}, \mathrm{~N}_{2} \mathrm{H}_{2}$, and $\mathrm{N}_{2} \mathrm{H}_{4}$ are available. ${ }^{27}$ They are all shown in Table 4 and the gas phase heat of formation of N14 and N18 are 2142.17 and $2959.60 \mathrm{~kJ} \mathrm{~mol}^{-1}$, respectively. Due to the great deal of nitrogen atoms that are connected directly, their enthalpy of formation is much higher than RDX, HMX, or CL-20, ${ }^{18}$ as shown in Table 7.

The heat of formation in the condensed phase of N14 and N18 can be calculated according to Equations (2) and (3), and they are 2048.49 and $2846.46 \mathrm{~kJ} \mathrm{~mol}^{-1}$, respectively. Related parameters are shown in Table 5.

\section{Crystal densities}

The crystal densities of N14 and N18 can be calculated according to Equation (4), and they are 1.784 and $1.817 \mathrm{~g} \mathrm{~cm}^{-3}$. Related parameters are shown in Table 6. As these two compounds contain mainly $\mathrm{C}$ and $\mathrm{N}$, and do not contain $\mathrm{O}$, and their densities are lower than HMX and CL-20, as shown in Table 7. The density of nitrogen-rich compounds without oxygen atoms is generally low. For instance, the density value of hydrogen azide $\left(\mathrm{HN}_{3}\right)$ and 5-amino$1 \mathrm{H}$-tetrazole is 1.12 and $1.71 \mathrm{~g} \mathrm{~cm}^{-3}$ respectively. ${ }^{27}$ When it comes to

Table 3. Energy gaps of some compounds

\begin{tabular}{|c|c|c|c|c|c|c|}
\hline \multirow[t]{2}{*}{ Comp } & \multicolumn{3}{|c|}{ B3LYP } & \multicolumn{3}{|c|}{$\omega B 97 X-D$} \\
\hline & LUMO(au) & $\operatorname{HOMO}(\mathrm{au})$ & $\Delta \mathrm{E}(\mathrm{au})$ & LUMO(au) & $\operatorname{HOMO}(\mathrm{au})$ & $\Delta \mathrm{E}(\mathrm{au})$ \\
\hline N14 & -0.10351 & -0.25456 & 0.15105 & -0.02412 & -0.32465 & 0.30053 \\
\hline N18 & -0.12522 & -0.27532 & 0.15010 & -0.05100 & -0.34487 & 0.29387 \\
\hline
\end{tabular}




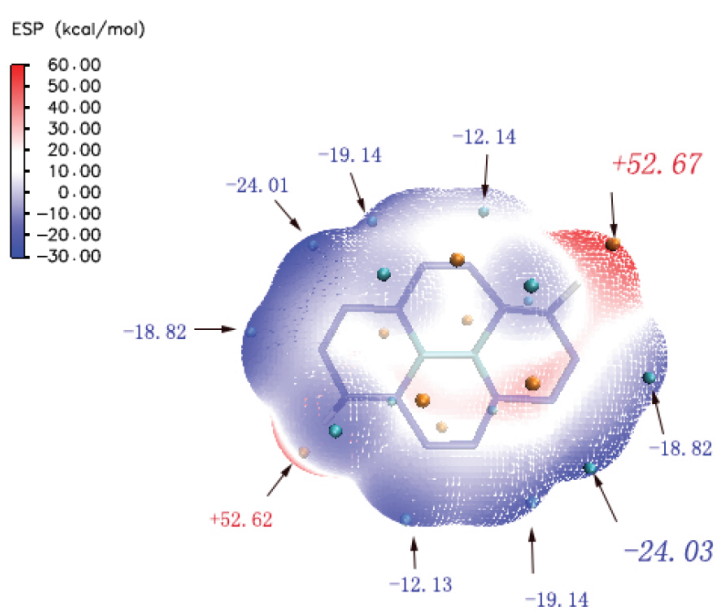

(a)

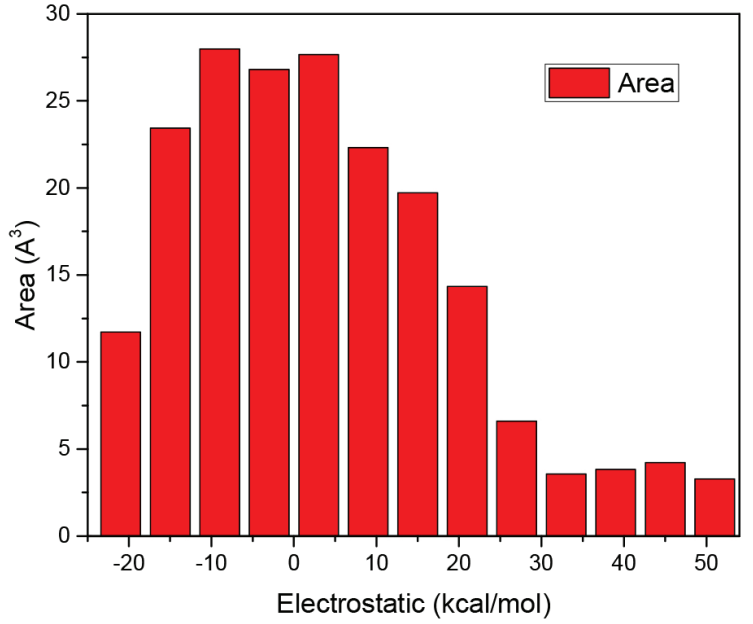

(b)

Figure 7. Electrostatic potentials map (a) and the surface areas (b) of N14

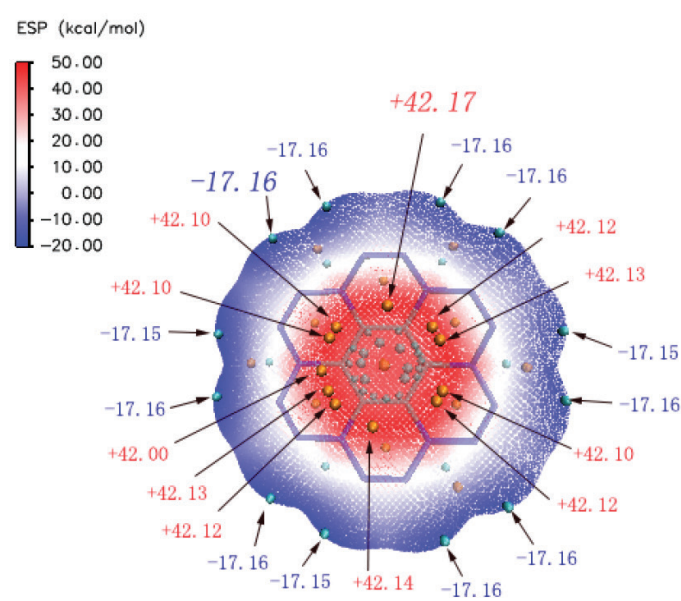

(a)

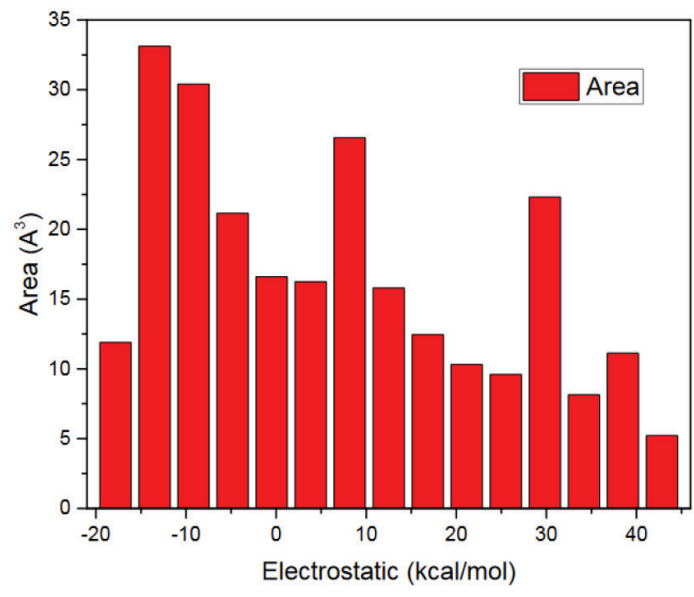

(b)

Figure 8. Electrostatic potentials map (a) and the surface area (b) of N18

Table 4. Related parameters for predicting gas phase heat of formation by isodesmic reactions

\begin{tabular}{ccccc}
\hline Comp & $\mathrm{E}_{\text {ZPE }}(\mathrm{au})$ & $\mathrm{H}_{\mathrm{T}}(\mathrm{au})$ & $\mathrm{E}_{0}(\mathrm{au})$ & $\begin{array}{c}\Delta \mathrm{H}_{\mathrm{f}}(\mathrm{g}) \\
\left(\mathrm{kJ} \mathrm{mol}^{-1}\right)\end{array}$ \\
\hline $\mathrm{N} 18$ & 0.119786 & 0.016010 & -1213.869725 & 2959.60 \\
$\mathrm{~N} 14$ & 0.101568 & 0.011946 & -843.6855212 & 2142.17 \\
$\mathrm{CH}_{4}$ & 0.044539 & 0.003813 & -40.53396275 & -74.60 \\
$\mathrm{NH}_{3}$ & 0.034252 & 0.003818 & -56.58272201 & -45.90 \\
$\mathrm{C}_{6} \mathrm{H}_{6}$ & 0.100085 & 0.005347 & -232.3113072 & 82.90 \\
$\mathrm{C}_{2} \mathrm{H}_{4}$ & 0.050775 & 0.003986 & -78.61553852 & 52.40 \\
$\mathrm{CH}_{3} \mathrm{NH}_{2}$ & 0.063782 & 0.004380 & -95.89388879 & 23.50 \\
$\mathrm{~N}_{2} \mathrm{H}_{2}$ & 0.027332 & 0.003801 & -110.6779937 & 197.07 \\
$\mathrm{~N}_{2} \mathrm{H}_{4}$ & 0.053284 & 0.004203 & -111.9106874 & 95.35 \\
\hline
\end{tabular}

traditional $\mathrm{CHON}$ materials, their heats derive from redox reaction and the density is an important parameter to power. ${ }^{28}$ But compounds mentioned in title are more like polynitrogen compounds, their heats derive from the deviation of bond energy of each nitrogen atom. ${ }^{8}$ Therefore, the density is not the primary focus.

\section{Detonation performance}

The detonation velocity (D), detonation pressure $(\mathrm{P})$, and heat of detonation (Q) of N14 and N18 are computed based on their crystal densities $(\rho)$ and condensed phase heats of formation $\Delta_{\mathrm{f}} \mathrm{H}(\mathrm{c})$. Their detonation performance, including RDX, HMX, and CL-20, ${ }^{29}$ are shown in Table 7. It is surprised that crystal density and heat of formation of N14 is lower than that of N18, but the detonation performance of the former is greater than that of the latter. Because the number mole of gaseous detonation products per gram of explosive

Table 5. Related parameters for predicting condensed phase heat of formation

\begin{tabular}{cccccc}
\hline Comp & $\begin{array}{c}\mathrm{A}_{\mathrm{s}} \\
\left(\AA^{2}\right)\end{array}$ & $\begin{array}{c}\sigma_{\text {tot }}^{2} \\
\left(\left[\mathrm{kcal} \mathrm{mol}^{-1}\right]^{2}\right)\end{array}$ & $\mathrm{v}$ & $\begin{array}{c}\mathrm{H}_{\text {sub }} \\
\left(\mathrm{kJ} \mathrm{mol}^{-1}\right)\end{array}$ & $\begin{array}{c}\Delta \mathrm{H}_{\mathrm{f}}(\mathrm{c}) \\
\left(\mathrm{kJ} \mathrm{mol}^{-1}\right)\end{array}$ \\
\hline $\mathrm{N} 18$ & 250.95424 & 170.1758509 & 0.11375910 & 113.14 & 2846.46 \\
$\mathrm{~N} 14$ & 195.50755 & 206.0047982 & 0.15147528 & 93.68 & 2048.49 \\
\hline
\end{tabular}


Table 6. Related parameters for predicting crystal densities

\begin{tabular}{lcccc}
\hline Comp & $\begin{array}{c}\mathrm{V}_{\mathrm{m}} \\
\left(\mathrm{cm}^{3} \mathrm{~mol}^{-1}\right)\end{array}$ & $\begin{array}{c}\mathrm{M} \\
\left(\mathrm{g} \mathrm{mol}^{-1}\right)\end{array}$ & $\begin{array}{c}\mathrm{v \sigma}^{2} \\
\left(\left[\mathrm{kcal} \mathrm{mol}^{-1}\right]^{2}\right)\end{array}$ & $\begin{array}{c}\rho_{\text {cry }} \\
\left(\mathrm{g} \mathrm{cm}^{-3}\right)\end{array}$ \\
\hline $\mathrm{N} 18$ & 173.12408 & 324 & 19.3590517 & 1.82 \\
$\mathrm{~N} 14$ & 122.81914 & 221 & 31.2046336 & 1.78 \\
\hline
\end{tabular}

plays a key role in detonation performance here. This resullt also reveals that detonation performance of N14 $\left(\mathrm{Q}=2214 \mathrm{cal} \mathrm{g}^{-1}\right.$ and $\left.\mathrm{D}=10,040 \mathrm{~m} \mathrm{~s}^{-1}\right)$ and N18 $\left(\mathrm{Q}=2114 \mathrm{cal} \mathrm{g}^{-1}\right.$ and $\left.\mathrm{D}=9400 \mathrm{~m} \mathrm{~s}^{-1}\right)$ are higher than that of CL-20, while their detonation pressures (43.6 GPa and $37.4 \mathrm{GPa}$ ) are lower. The title compounds can decompose into large amount of nitrogen gas, which contributes to their detonation performance. Nitrogen-rich molecules are thus designed to promising materials. Fox example, dinitropyrazole fused 1,2,3,4-tetrazine has a performance $\left(\mathrm{D}=9631 \mathrm{~m} \mathrm{~s}^{-1}, \mathrm{P}=44.0 \mathrm{GPa}\right)$ comparable to CL-20. ${ }^{30}$

Table 7. Performance parameters of HEDMs

\begin{tabular}{cccccc}
\hline Comp & $\begin{array}{c}\rho \\
\left(\mathrm{g} \mathrm{cm}^{-3}\right)\end{array}$ & $\begin{array}{c}\Delta_{\mathrm{f}} \mathrm{H}(\mathrm{c}) \\
\left(\mathrm{kJ} \mathrm{mol}^{-1}\right)\end{array}$ & $\begin{array}{c}\mathrm{Q} \\
\left(\mathrm{cal} \mathrm{g}^{-1}\right)\end{array}$ & $\begin{array}{c}\mathrm{D} \\
\left(\mathrm{m} \mathrm{s}^{-1}\right)\end{array}$ & $\begin{array}{c}\mathrm{P} \\
(\mathrm{GPa})\end{array}$ \\
\hline $\mathrm{N} 18$ & 1.82 & 2846.46 & 2114 & 9400 & 37.4 \\
$\mathrm{~N} 14$ & 1.78 & 2048.49 & 2214 & 10,040 & 43.6 \\
$\mathrm{RDX}^{\mathrm{a}}$ & 1.80 & 79.00 & 1501 & 8750 & 34.7 \\
$\mathrm{HMX}^{\mathrm{a}}$ & 1.90 & 102.41 & 1498 & 9100 & 39.3 \\
$\varepsilon-\mathrm{CL}^{2} 0^{\mathrm{a}}$ & 2.04 & 377.04 & 1567 & 9380 & 44.1 \\
\hline
\end{tabular}

${ }^{\mathrm{a}}$ The detonation performance values are from reference. ${ }^{29}$

\section{Impact sensitivity}

The values $(\mathrm{cm})$ of $\mathrm{h}_{50 \%}$ are estimated through the method and the results are summarized in Table 8 . The calculated sensitivity of CL-20 is $9 \mathrm{~cm}$, closing to measured value. ${ }^{16}$ The values of title compounds are 23 and $32 \mathrm{~cm}$ respectively, and higher than CL-20. Therefore, the N14 and N18 are more insensitivity than CL-20. Compounds in which many nitrogen atoms are directly connected are all sensitive to impact, and a common example is lead azide. ${ }^{31}$ But when these nitrogen atoms constitute a fused ring, the sensitivity will be improved. ${ }^{30,32}$

\section{SYNTHETIC ROUTES}

It is well known ${ }^{33,34}$ that the N-F bond is weak to break, and
Table 8. Impact sensitivities of title compounds and CL-20

\begin{tabular}{ccccc}
\hline Comp & $\begin{array}{c}\sigma_{+}{ }^{2} \\
\left(\left[\mathrm{kcal} \mathrm{mol}^{-1}\right]^{2}\right)\end{array}$ & $v$ & $\mathrm{~h}_{\text {cal }}(\mathrm{cm})$ & $\mathrm{h}_{\text {exp }}(\mathrm{cm})$ \\
\hline CL-20 & 246.03124 & 0.05923738 & 9 & $14^{\mathrm{a}}$ \\
$\mathrm{N} 18$ & 147.90124 & 0.1137591 & 23 & - \\
$\mathrm{N} 14$ & 167.66452 & 0.15147528 & 32 & - \\
\hline
\end{tabular}

${ }^{\text {a }}$ The value is from reference. ${ }^{16}$

then hydrogen fluoride is eliminated. Based on that, polynitrogen material $\mathrm{N}_{5}{ }^{+}$was synthesized. ${ }^{8}$ The same method is also used to produce the title compounds and two possible routes were proposed in Figure 9 and 10. In the two schemes, tetraaminoethylenes, ${ }^{35}$ hexaaminobenzene, ${ }^{36}$ monofluoroamin, ${ }^{37}$ and 1,2-difluorodiazine ${ }^{38}$ are obtained in accordance with previous papers.

\section{CONCLUSIONS}

In this work, N14 and N18 are calculated by the Gaussian 09 package with the B3LYP method with the 6-311++G (d, p) basis set to investigate their detonation performance and stability. The results show that the detonation performance of N14 (P = 43.6 GPa, D = 10,040 m $\left.\mathrm{s}^{-1}, \mathrm{Q}=2214 \mathrm{cal} \mathrm{g}^{-1}\right)$ and $\mathrm{N} 18\left(\mathrm{P}=37.4 \mathrm{GPa}, \mathrm{D}=9400 \mathrm{~m} \mathrm{~s}^{-1}, \mathrm{Q}=2114\right.$ $\mathrm{cal} \mathrm{g}^{-1}$ ) are comparable to the value of CL-20. All the atoms in the two compounds may form a special conjugated system although they are non-coplanar, and this requires further discussion. Considering both the detonation properties and relative stabilities, they are all likely to be used as candidates of high energy density materials with modest impact sensitivity and high performance, and these results can also be used for comparisons with properties of other familiar explosives, and provide theoretical support for the molecular design of novel high energetic density compounds. Further work on route optimization and practical synthesis is being carried out by our team.

\section{SUPPLEMENTARY MATERIAL}

Tables $1 \mathrm{~S}-4 \mathrm{~S}$ can be freely accessed at http://www.quimicanova. sbq.org.br, in PDF format.

\section{ACKNOWLEDGEMENTS}

This work was supported by the National Natural Science Foundation of China (NO.21576026).<smiles></smiles>

Figure 9. A possible route to prepare N14

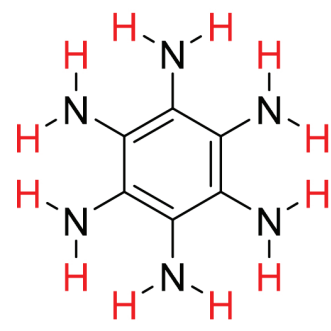<smiles>CCCCCCC</smiles>

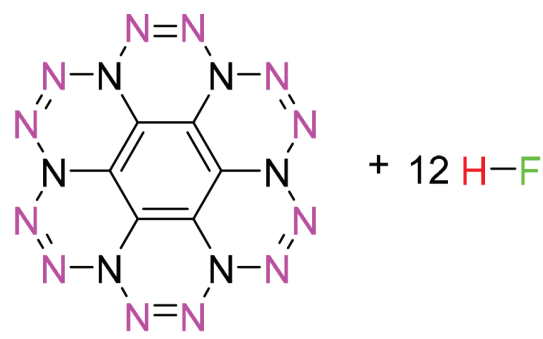

Figure 10. A possible route to prepare N18 


\section{REFERENCES}

1. Dong, Y.; Peng, P.; Hu, B.; Su, H.; Li, S.; Pang, S.; Molecules 2017, 22.

2. Lv, P.; Tong, Y.; Wang, H.; Dang, L.; Sun, C.; Pang, S.; J. Mol. Liq. 2017, 231, 192.

3. Chen, J.; Yu, Y.; Li, Y.; Pang, S.; J. Fluorine Chem. 2018, 205, 35.

4. Zhang, Q.; Shreeve, J. M.; Angew. Chem., Int. Ed. Engl. 2013, 52, 8792.

5. Xu, Y.; Wang, Q.; Shen, C.; Lin, Q.; Wang, P.; Lu, M.; Nature 2017, 549, 78.

6. Meng, L.; Lu, Z.; Wei, X.; Xue, X.; Ma, Y.; Zeng, Q.; Fan, G.; Nie, F.; Zhang, C.; CrystEngComm 2016, 18, 2258.

7. Christe, K. O.; Propellants, Explos., Pyrotech. 2007, 32, 194.

8. Christe, K. O.; Wilson, W. W.; Sheehy, J. A.; Boatz, J. A.; Angew. Chem., Int. Ed. 2001, 40, 2947.

9. Eremets, M. I.; Gavriliuk, A. G.; Trojan, I. A.; Dzivenko, D. A.; Boehler, R.; Nat. Mater. 2004, 3, 558.

10. Zhang, C.; Sun, C.; Hu, B.; Yu, C.; Lu, M.; Science 2017, 355, 374.

11. Zhang, W.; Wang, K.; Li, J.; Lin, Z.; Song, S.; Huang, S.; Liu, Y.; Nie, F.; Zhang, Q.; Angew. Chem., Int. Ed. Engl. 2018, 57, 2592.

12. Strout, D. L.; J. Phys. Chem. A 2002, 106, 816.

13. Mondal, S.; Srinivasu, K.; Ghosh, S. K.; Chattaraj, P. K.; RSC Adv. 2013, 3, 6991 .

14. Tawar, T.; Kerim, A.; Fullerenes, Nanotubes, Carbon Nanostruct. 2015, 23, 846 .

15. Frisch, M. J.; Trucks, G. W.; Schlegel, H. B.; Scuseria, G. E.; Robb, M. A.; Cheeseman, J. R.; Scalmani, G.; Barone, V.; Petersson, G. A.; Nakatsuji, H.; Li, X.; Caricato, M.; Marenich, A. V.; Bloino, J.; Janesko, B. G.; Gomperts, R.; Mennucci, B.; Hratchian, H. P.; Ortiz, J. V.; Izmaylov, A. F.; Sonnenberg, J. L.; Williams-Young, D.; Ding, F.; Lipparini, F.; Egidi, F.; Goings, J.; Peng, B.; Petrone, A.; Henderson, T.; Ranasinghe, D.; Zakrzewski, V. G.; Gao, J.; Rega, N.; Zheng, G.; Liang, W.; Hada, M.; Ehara, M.; Toyota, K.; Fukuda, R.; Hasegawa, J.; Ishida, M.; Nakajima, T.; Honda, Y.; Kitao, O.; Nakai, H.; Vreven, T.; Throssell, K.; Montgomery, J. A., Jr.; Peralta, J. E.; Ogliaro, F.; Bearpark, M. J.; Heyd, J. J.; Brothers, E. N.; Kudin, K. N.; Staroverov, V. N.; Keith, T. A.; Kobayashi, R.; Normand, J.; Raghavachari, K.; Rendell, A. P.; Burant, J. C.; Iyengar, S. S.; Tomasi, J.; Cossi, M.; Millam, J. M.; Klene, M.; Adamo, C.; Cammi, R.; Ochterski, J. W.; Martin, R. L.; Morokuma,
K.; Farkas, O.; Foresman, J. B.; Fox, D. J.; Gaussian 09 Revision A.1., Gaussian Inc, 2009.

16. He, P.; Zhang, J. G.; Wang, K.; Yin, X.; Zhang, T. L.; J. Org. Chem. 2015, 80,5643 .

17. He, P.; Zhang, J. G.; Wu, L.; Wu, J. T.; Zhang, T. L.; J. Phys. Org. Chem. 2017, 30, 3674

18. Qi, C.; Li, S. H.; Li, Y. C.; Wang, Y.; Zhao, X. X.; Pang, S. P.; Chem. Eur. J. 2012, 18, 16562.

19. Lin, H.; Zhu, Q.; Huang, C.; Yang, D.; Lou, N.; Zhu, S.; Li, H.; Struct. Chem. 2019.

20. Jin, X.; Zhou, J.; Wang, S.; Hu, B.; Quim. Nova 2016, 39, 467.

21. Humphrey, W.; Dalke, A.; Schulten, K.; J. Mol. Graphics 1996, 14, 33.

22. Lu, T.; Chen, F.; J. Comput. Chem. 2012, 33, 580.

23. Byrd, E. F. C.; Rice, B. M.; J. Phys. Chem. A 2006, 110, 1005.

24. Politzer, P.; Martinez, J.; Murray, J. S.; Concha, M. C.; Toro-Labbé, A.; Mol. Phys. 2009, 107, 2095.

25. Tsai, C.; Su, Y.; Li, G.; Chai, J.; Phys. Chem. Chem. Phys. 2013, 15, 8352.

26. Pospisil, M.; Vavra, P.; Concha, M. C.; Murray, J. S.; Politzer, P.; J. Mol. Model. 2010, 16, 895.

27. https://webbook.nist.gov/chemistry/, accessed in August 2019.

28. Kamlet, M. J.; Jacobs, S. J.; J. Chem. Phys. 1967, 48, 1.

29. Politzer, P.; Murray, J. S.; Cent. Eur. J. Energ. Mater. 2011, 8, 209.

30. Tang, Y.; Kumar, D.; Shreeve, J. M.; J. Am. Chem. Soc. 2017, 139, 13684.

31. Deng, M.; Feng, Y.; Zhang, W.; Qi, X.; Zhang, Q.; Nat. Commun. 2019, 10, 1339.

32. Li, Y. C.; Qi, C.; Li, S. H.; Zhang, H. J.; Sun, C. H.; Yu, Y. Z.; Pang, S. P.; J. Am. Chem. Soc. 2010, 132, 12172.

33. Belter, R. K.; J. Fluorine Chem. 2011, 132, 961.

34. Peng, W.; Shreeve, J. M.; J. Org. Chem. 2005, 70, 5760.

35. Winberg, H. E.; Carnahan, J. E.; Coffman, D. D.; Brown, M.; J. Am. Chem. Soc. 1965, 87, 2055.

36. Lahiri, N.; Lotfizadeh, N.; Tsuchikawa, R.; Deshpande, V. V.; Louie, J.; J. Am. Chem. Soc. 2017, 139, 19.

37. Minkwitz, R.; Nass, R.; ChemInform 1989, 20.

38. Sanborn, R. H.; J. Chem. Phys. 1960, 33, 1855. 